\title{
Functional status, pre-dialysis health and clinical outcomes among elderly dialysis patients
}

\author{
Silvi Shah ${ }^{1 *}$ (D), Anthony C. Leonard ${ }^{2}$ and Charuhas V. Thakar ${ }^{1,3}$
}

\begin{abstract}
Background: Elderly patients comprise the fastest growing population initiating dialysis in United States. The impact of poor functional status and pre-dialysis health status on clinical outcomes in elderly dialysis patients is not well studied.
\end{abstract}

Methods: We studied a retrospective cohort of 49,645 incident end stage renal disease patients that initiated dialysis between January 1, 2008 and December 31, 2008 from the United States Renal Data System with linked Medicare data covering at least 2 years prior to dialysis initiation. Using logistic regression models adjusted for pre-dialysis health status and other cofounders, we examined the impact of poor functional status as defined from form 2728 on 1-year all-cause mortality as primary outcome, type of dialysis modality (hemodialysis vs. peritoneal dialysis), and type of initial vascular access (arteriovenous access vs. central venous catheter) among hemodialysis patients as secondary outcomes.

Results: Mean age was $72 \pm 11$ years. At dialysis initiation, 18.7\% reported poor functional status, $88.9 \%$ had at least 1 pre-dialysis hospitalization, and $27.8 \%$ did not receive pre-dialysis nephrology care. In adjusted analyses, 1-year mortality was higher in patients with poor functional status $(\mathrm{OR}, 1.48 ; 95 \% \mathrm{Cl}, 1.40-1.57)$. Adjusted odds of being initiated on hemodialysis than peritoneal dialysis (odds ratio [OR], 1.39; 95\% confidence interval $[\mathrm{Cl}], 1.16-1.66)$ were higher in patients with poor functional status. Poor functional status decreased the adjusted odds of starting hemodialysis with arteriovenous access as compared to central venous catheter (OR, 0.79; 95\% Cl, 0.72-0.86).

Conclusion: Poor functional status in elderly patients with end stage renal disease is associated with higher odds of initiating hemodialysis; increases the risk of central venous catheter use, and is an independent predictor of 1-year mortality.

Keywords: Functional status, Elderly, Mortality, Vascular access, and Dialysis

\section{Background}

Elderly chronic kidney disease (CKD) patients defined as $\geq 60$ years of age represent the fastest growing segment of the incident end stage renal disease (ESRD) population in United States, with more than half of incident dialysis patients being over 65 years of age [1]. The annual mortality in patients with ESRD is about $20 \%$, and is higher in the first few months after the initiation of

\footnotetext{
* Correspondence: shah2sv@ucmail.uc.edu

${ }^{1}$ Division of Nephrology and Hypertension, University of Cincinnati, 231

Albert Sabin Way, Cincinnati, OH 45267, USA

Full list of author information is available at the end of the article
}

dialysis than after this period [2]. Older age is independently associated with a 5 fold increase in odds of death within 90 days of dialysis initiation [3]. Even though, early mortality is a significant problem among elderly ESRD patients, it remains under recognized [4]. Since most of the deaths occur within the first year of initiating dialysis, it is plausible that health conditions present prior and during dialysis initiation impact post-dialysis outcomes [2].

Activities of daily living are one of the most important prognostic factors that influence long-term outcomes $[5,6]$. Functional status is commonly defined as an individual's ability to perform normal activities of daily living required

(C) The Author(s). 2018 Open Access This article is distributed under the terms of the Creative Commons Attribution 4.0 International License (http://creativecommons.org/licenses/by/4.0/), which permits unrestricted use, distribution, and 
to meet basic needs, and maintain well-being [7]. Poor functional status is prevalent in older patients with chronic kidney disease, and is independently associated with a higher risk of death [8]. Comorbidities and acute care hospitalizations are frequent in elderly CKD patients, may lead to poor pre-dialysis health, and independently increase the risk of death [9-11]. Furthermore, initiation of dialysis is linked to decline in functional status in elderly patients with ESRD, and therefore can impact quality of life [6]. Although studies have examined clinical outcomes of elderly dialysis patients, the impact of functional status and pre-dialysis health including pre-dialysis acute hospitalization at incident dialysis on post-ESRD outcomes has not been studied.

The main objective of this study was to determine the impact of poor functional status on key clinical outcomes in elderly patients who get initiated on dialysis, after taking into account their pre-dialysis health including pre-dialysis acute hospitalizations. Using the most comprehensive national database of dialysis patients in United States, the United System Renal Data System (USRDS) with linked Medicare information, we hypothesized that poor functional status along with poor pre-dialysis health at the time of dialysis initiation is associated with higher mortality in ESRD patients. Additionally, we examined the impact of poor functional status with type of dialysis modality as well as type of vascular access during hemodialysis initiation.

\section{Methods}

\section{Study population and study design}

We included 49,645 patients $\geq 18$ years, who initiated hemodialysis or peritoneal dialysis between January 1, 2008 and December 31, 2008 from the USRDS, and had both Medicare Part A and Part B coverage as their insurer at least 2 years prior to dialysis initiation. The cohort was predominantly older adults ( $\geq 60$ years of age), and therefore hereby referred to as elderly in the present study. The data was obtained by a formal request to USRDS. The USRDS required the institutional review board to review the request, and the study was deemed exempt by University of Cincinnati institutional review board. We excluded patients $<18$ years old and those with renal transplants. Patients with missing information on race and missing information on dialysis access were also excluded. Figure 1 shows the derivation of the study cohort.

\section{Exposure of interest}

Our major predictor was poor functional status defined by any of the three co-morbid conditions as specified in form CMS-2728 - (1) inability to ambulate, (2) inability to transfer or (3) need of assistance with daily activities, as described in the prior studies $[4,12,13]$.

\section{Primary and secondary outcomes}

Primary outcome was 1-year all-cause mortality after the ESRD initiation date. Secondary outcomes examined were - type of dialysis modality (hemodialysis vs. peritoneal dialysis $[\mathrm{PD}]$ ) and type of initial vascular access (arteriovenous [AV] access vs. central venous catheter $[\mathrm{CVC}])$ among hemodialysis patients. Patients were followed from dialysis initiation to death, or censored at the end of our death records, December 31, 2010 (two to 3 years post-ESRD).

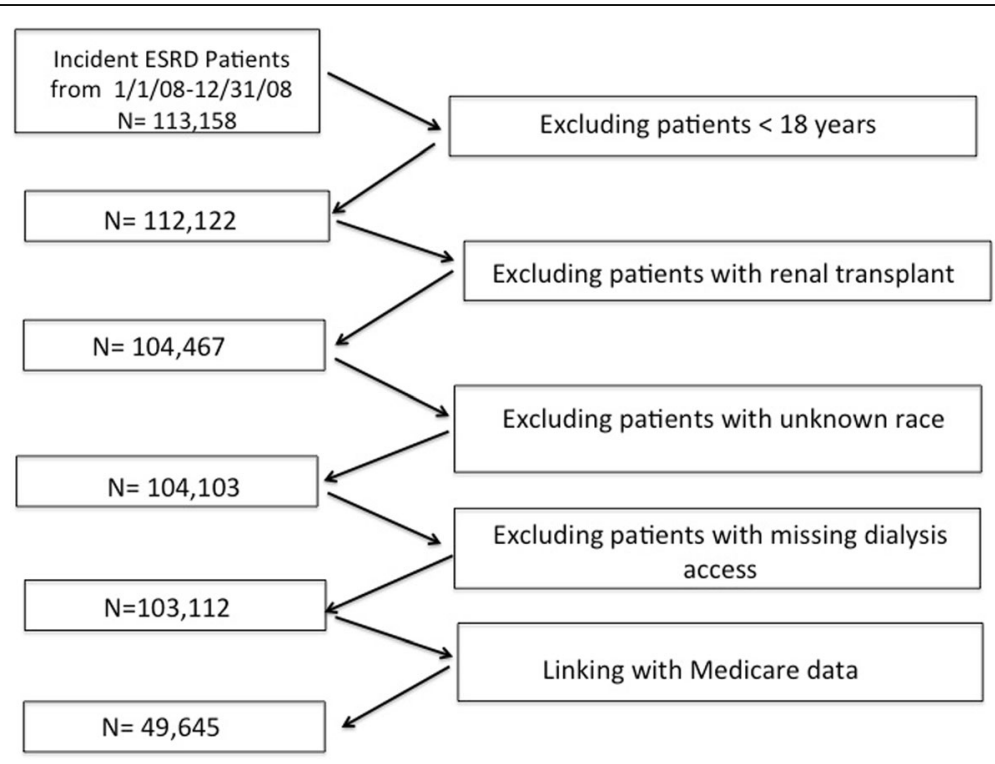

Fig. 1 Flow chart describing the derivation of the study cohort 
Table 1 Characteristics of patients who initiated dialysis in 2008 stratified by poor functional status and good functional status

\begin{tabular}{|c|c|c|c|c|}
\hline Variable & All & Poor functional status & Good functional status & $P$ value \\
\hline Number of Subjects & 49,645 & $9295(18.7 \%)$ & $40,350(81.3 \%)$ & \\
\hline \multicolumn{5}{|l|}{ Mortality, \% } \\
\hline 90-Day & 11.6 & 19.3 & 9.8 & $<0.001$ \\
\hline 1-Year & 31.2 & 46.4 & 27.7 & $<0.001$ \\
\hline \multicolumn{5}{|l|}{ Demographics } \\
\hline Age (years) & $72(11)$ & $73(11)$ & $71(11)$ & $<0.001$ \\
\hline $18-29$ & 0.2 & 0.2 & 0.2 & $<0.001$ \\
\hline $30-39$ & 1.2 & 0.8 & 1.2 & \\
\hline $40-49$ & 3.4 & 2.4 & 3.6 & \\
\hline $50-59$ & 9.1 & 8.3 & 9.3 & \\
\hline $60-69$ & 23.6 & 21.1 & 24.2 & \\
\hline $70-79$ & 36.9 & 35.3 & 37.3 & \\
\hline $80-89$ & 23.6 & 28.9 & 22.4 & \\
\hline $90-100$ & 2.0 & 3.0 & 1.8 & \\
\hline Octogenarians, \% & 25.6 & 31.9 & 24.2 & $<0.001$ \\
\hline Body mass index $\left(\mathrm{kg} / \mathrm{m}^{2}\right)$ & $28.7(7.7)$ & $28.9(8.4)$ & $28.6(7.5)$ & 0.002 \\
\hline$<18.5$ & 3.7 & 4.9 & 3.4 & $<0.001$ \\
\hline $18.5-24.99$ & 31.8 & 32.0 & 31.8 & \\
\hline $25-30$ & 28.5 & 25.4 & 29.3 & \\
\hline$>30$ & 34.4 & 35.8 & 34.0 & \\
\hline Missing & 1.6 & 1.9 & 1.6 & \\
\hline Male, \% & 54.6 & 48.8 & 55.9 & $<0.001$ \\
\hline Race, \% & & & & 0.59 \\
\hline Hispanic & 9.3 & 9.7 & 9.2 & \\
\hline White & 62.3 & 61.8 & 62.4 & \\
\hline Black & 24.5 & 24.6 & 24.5 & \\
\hline Asian & 3.0 & 2.9 & 3.0 & \\
\hline Native American & 0.9 & 1.0 & 0.9 & \\
\hline \multicolumn{5}{|l|}{ Comorbidities, \% } \\
\hline Congestive heart failure & 40.8 & 52.8 & 38.0 & $<0.001$ \\
\hline ASHD & 42.9 & 53.6 & 40.4 & $<0.001$ \\
\hline Hypertension & 85.2 & 86.5 & 84.9 & $<0.001$ \\
\hline Diabetes mellitus & 56.2 & 63.4 & 54.5 & $<0.001$ \\
\hline Cancer & 9.8 & 10.7 & 9.5 & $<0.001$ \\
\hline Amputation & 3.5 & 8.1 & 2.5 & $<0.001$ \\
\hline Peripheral vascular disease & 18.1 & 26.4 & 16.2 & $<0.001$ \\
\hline TIA/CVA & 12.4 & 21.0 & 10.4 & $<0.001$ \\
\hline COPD & 12.6 & 18.7 & 11.2 & $<0.001$ \\
\hline \multicolumn{5}{|l|}{ Dialysis modality, \% } \\
\hline Hemodialysis & 95.9 & 98.4 & 95.3 & $<0.001$ \\
\hline Peritoneal dialysis & 4.1 & 1.6 & 4.7 & \\
\hline
\end{tabular}


Table 1 Characteristics of patients who initiated dialysis in 2008 stratified by poor functional status and good functional status (Continued)

\begin{tabular}{|c|c|c|c|c|}
\hline Variable & All & Poor functional status & Good functional status & $P$ value \\
\hline \multicolumn{5}{|l|}{ Hemodialysis access, \% } \\
\hline AV access & 17.7 & 10.7 & 19.3 & \multirow[t]{2}{*}{$<0.001$} \\
\hline Central venous catheter & 82.3 & 89.3 & 80.7 & \\
\hline Maturing AV access (among CVC) & 21.4 & 17.2 & 22.4 & $<0.001$ \\
\hline \multicolumn{5}{|c|}{ Laboratory variables from within 45-day period prior to most recent ESRD episode } \\
\hline Albumin, $\mathrm{g} / \mathrm{dL}$ & $3.1(0.7)$ & $2.9(0.7)$ & $3.2(0.7)$ & $<0.001$ \\
\hline$<3.5$ & 51.8 & 60.5 & 49.7 & \multirow[t]{3}{*}{$<0.001$} \\
\hline$\geq 3.5$ & 25.3 & 16.8 & 27.2 & \\
\hline Missing & 23.0 & 22.7 & 23.0 & \\
\hline Hemoglobin, g/dL & $10.0(1.5)$ & $9.9(1.5)$ & $10.1(1.5)$ & $<0.001$ \\
\hline$<11$ & 68.3 & 71.8 & 67.5 & \multirow[t]{4}{*}{$<0.001$} \\
\hline $11-12$ & 15.1 & 13.3 & 15.5 & \\
\hline$>12$ & 8.5 & 8.0 & 8.6 & \\
\hline Missing & 8.1 & 6.9 & 8.4 & \\
\hline \multicolumn{5}{|l|}{ Dialysis setting, \% } \\
\hline Dialysis facility & 95.0 & 95.7 & 94.8 & \multirow[t]{3}{*}{$<0.001$} \\
\hline Home & 4.3 & 1.9 & 4.8 & \\
\hline Skilled nursing facility & 0.7 & 2.3 & 0.4 & \\
\hline \multicolumn{5}{|l|}{ Employment status, \% } \\
\hline Unemployed & 11.1 & 10.5 & 11.2 & \multirow[t]{4}{*}{$<0.001$} \\
\hline Employed + others & 5.9 & 5.0 & 6.1 & \\
\hline Retired-age & 61.6 & 61.0 & 61.7 & \\
\hline Retired-disability & 21.4 & 23.5 & 20.9 & \\
\hline \multicolumn{5}{|c|}{ Acute hospitalization during 2- year pre-ESRD } \\
\hline Frequency, \% & 88.9 & 93.8 & 87.8 & $<0.001$ \\
\hline Total length of stay (days) & $23(28)$ & $36(36)$ & $20(25)$ & $<0.001$ \\
\hline \multicolumn{5}{|l|}{ Pre-dialysis nephrology care, \% } \\
\hline None & 27.8 & 35.3 & 26.1 & \multirow[t]{4}{*}{$<0.001$} \\
\hline$<12$ months & 33.0 & 28.2 & 34.2 & \\
\hline$>12$ months & 26.3 & 21.3 & 27.5 & \\
\hline Unknown & 12.8 & 15.1 & 12.3 & \\
\hline \multicolumn{5}{|l|}{ Cause of end stage renal disease, $\%$} \\
\hline Diabetes mellitus & 45.9 & 49.7 & 45.1 & \multirow[t]{8}{*}{$<0.001$} \\
\hline Hypertension/LVD & 32.3 & 29.9 & 32.8 & \\
\hline Malignancy & 2.6 & 2.0 & 2.8 & \\
\hline Cystic/hereditary & 1.3 & 0.6 & 1.4 & \\
\hline Secondary GN /vasculits & 1.2 & 0.9 & 1.3 & \\
\hline Glomerulonephritis & 3.9 & 2.2 & 4.3 & \\
\hline Interstitial nephritis/pyelonephritis & 2.9 & 2.8 & 2.9 & \\
\hline Others & 9.8 & 11.8 & 9.3 & \\
\hline
\end{tabular}


Table 1 Characteristics of patients who initiated dialysis in 2008 stratified by poor functional status and good functional status (Continued)

\begin{tabular}{|c|c|c|c|c|}
\hline Variable & All & Poor functional status & Good functional status & $P$ value \\
\hline \multicolumn{5}{|c|}{ Cause of death (among patients with 1-year mortality), \% } \\
\hline Cardiovascular & 38.2 & 37.1 & 38.7 & $<0.001$ \\
\hline Infection & 10.0 & 12.1 & 9.2 & \\
\hline Malignancy & 4.5 & 3.1 & 5.0 & \\
\hline Withdrawal of dialysis & 11.6 & 11.6 & 11.7 & \\
\hline Unknown/others & 35.6 & 36.1 & 35.4 & \\
\hline History of nursing home, \% & 10.3 & 38.2 & 3.9 & $<0.001$ \\
\hline Provision of transplant information, $\%$ & 65.6 & 55.5 & 67.9 & $<0.001$ \\
\hline
\end{tabular}

Data are presented in mean (SD) or proportion where appropriate. CVA/TIA cerebrovascular accident/transient ischemic attack, COPD chronic obstructive pulmonary disease, AV arteriovenous, CVC central venous catheter, LVD large vessel disease, GN glomerulonephritis

\section{Covariates}

Form CMS-2728 was used to obtain information on dialysis modality, vascular access at hemodialysis initiation, ESRD cause, comorbidities (during the last 10 years), laboratory data, nursing home history, predialysis nephrology care, and history of unemployment. For regression model analyses, we collapsed incident vascular access into two groups - AV access (including AV fistula and AV graft) vs. CVC (including others). We included the following covariates to determine the pre-dialysis health in patients with ESRD: pre-dialysis acute care hospitalizations, pre-dialysis nephrology care, nursing home residence, comorbidities, and laboratory data (serum hemoglobin and serum albumin within 45 days prior to most recent ESRD episode). Pre-ESRD Medicare claims was used to obtain information on acute hospitalizations during the 2 years preceding ESRD. The present analysis fell within the scope of the data acquisition, and institutional review board approval, whereby pre-ESRD information for up to 2 years prior to incident dialysis was available for the study period (January 1, 2008 and December 31, 2008), and therefore included in the study design. Comorbidities examined included congestive heart failure, atherosclerotic heart disease which included other cardiac disease, hypertension, diabetes mellitus, cancer, peripheral vascular disease, transient ischemic attack/ cerebrovascular accident, chronic obstructive pulmonary disease and amputation [1].

\section{Statistical analyses}

All data were analyzed using SAS (SAS Institute, Cary, NC). Summary statistics are presented as percentages for categorical data and mean \pm standard deviation (SD) for continuous variables. Differences between groups were tested with chi-squared tests for categorical variables and t-tests or one-way ANOVAs for continuous variables. Multivariable logistic regression was used to derive the risk estimates from models, which included covariates, expressed as OR with 95\% CI. Statistical significance was set at a two-tailed $p$-value of 0.05 , unadjusted for multiple tests. Kaplan-Meier methods were used to construct unadjusted survival curves, and the survival rates of different groups were compared using a log-rank test. Using logistic regression models adjusted for pre-dialysis health status and other covariates, we examined the impact of poor functional status on hemodialysis vs. PD and in separate model among hemodialysis patients; we studied the effect of functional status on AV access vs. CVC. When using dialysis modality and access-type to predict death we used a 3group covariate (PD, AV hemodialysis access, and CVC hemodialysis access). Predictor variables in the logistic regression models included demographics, comorbidities, laboratory data, ESRD cause, nursing home residence, unemployment history, transplant information provision, pre-ESRD nephrology care and pre-ESRD acute hospitalizations. Additionally, a Cox proportional hazard model, which included the same covariates as above, was used to study the impact of poor functional status on mortality. Finally, for purposes of examining its association with survival, we constructed a simple mortality risk score for each patient (ranging from zero to three), composed of patient's count of three risk factors: poor functional status, octogenarian status, and history of any hospitalization during the 2 years pre-ESRD. Risk factors of functional status, octogenarian status and pre-dialysis hospitalization were chosen based on clinical relevance. Kaplan-Meier survival curves were estimated (1) comparing patients with and without poor functional status; and (2) comparing patients with four levels of risk scores.

\section{Results}

Baseline characteristics of study cohort

Clinical characteristics and demographics for the study population are shown in Table 1 . The mean age was $72 \pm 11$ years. Of the study sample; $54.6 \%$ were male, $24.5 \%$ were Black, and $25.6 \%$ were octogenarian. With 
Table 2 Characteristics of patients who initiated dialysis in 2008 stratified by 1-year mortality

\begin{tabular}{|c|c|c|c|c|}
\hline Variable & All & Death $\leq 1$ year & Death $>1$ year & $P$ value \\
\hline Number of Subjects & 49,645 & $15,513(31.2 \%)$ & $34,132(68.8 \%)$ & \\
\hline \multicolumn{5}{|l|}{ Functional status, \% } \\
\hline Poor functional status & 18.7 & 27.8 & 14.6 & $<0.001$ \\
\hline \multicolumn{5}{|l|}{ Demographics } \\
\hline Age (years) & $72(11)$ & $75(10)$ & $70(12)$ & $<0.001$ \\
\hline $18-29$ & 0.2 & 0.1 & 0.3 & $<0.001$ \\
\hline $30-39$ & 1.2 & 0.5 & 1.4 & \\
\hline $40-49$ & 3.4 & 1.7 & 4.2 & \\
\hline $50-59$ & 9.1 & 5.7 & 10.6 & \\
\hline $60-69$ & 23.6 & 18.2 & 26.1 & \\
\hline 70-79 & 36.9 & 38.1 & 36.3 & \\
\hline $80-89$ & 23.6 & 32.1 & 19.7 & \\
\hline $90-100$ & 2.0 & 3.4 & 1.4 & \\
\hline Octogenarians, \% & 25.6 & 35.6 & 21.1 & $<0.001$ \\
\hline Body mass index, $\mathrm{kg} / \mathrm{m}^{2}$ & $28.7(7.7)$ & 7.5 & $29.1(7.7)$ & $<0.001$ \\
\hline$<18.5$ & 3.7 & 5.2 & 3.0 & $<0.001$ \\
\hline $18.5-24.99$ & 31.8 & 36.5 & 29.7 & \\
\hline $25-30$ & 28.5 & 27.2 & 29.1 & \\
\hline$>30$ & 34.4 & 29.5 & 36.6 & \\
\hline Missing & 1.6 & 1.7 & 1.6 & \\
\hline Male, \% & 54.6 & 55.6 & 54.1 & 0.003 \\
\hline Race, \% & & & & $<0.001$ \\
\hline Hispanic & 9.3 & 7.1 & 10.3 & \\
\hline White & 62.3 & 70.2 & 58.7 & \\
\hline Black & 24.5 & 19.5 & 26.7 & \\
\hline Asian & 3.0 & 2.3 & 3.3 & \\
\hline Native American & 0.9 & 0.8 & 1.0 & \\
\hline \multicolumn{5}{|l|}{ Comorbidities, \% } \\
\hline Congestive heart failure & 40.8 & 49.1 & 37.0 & $<0.001$ \\
\hline ASHD & 42.9 & 48.7 & 40.2 & $<0.001$ \\
\hline Hypertension & 85.2 & 81.3 & 87.0 & $<0.001$ \\
\hline Diabetes mellitus & 56.2 & 52.4 & 57.9 & $<0.001$ \\
\hline Cancer & 9.8 & 12.5 & 8.5 & $<0.001$ \\
\hline Amputations & 3.5 & 3.8 & 3.4 & 0.03 \\
\hline Peripheral vascular disease & 18.1 & 20.7 & 16.9 & $<0.001$ \\
\hline TIA/CVA & 12.4 & 14.0 & 11.6 & $<0.001$ \\
\hline COPD & 12.6 & 16.8 & 10.7 & $<0.001$ \\
\hline \multicolumn{5}{|l|}{ Dialysis modality, \% } \\
\hline Hemodialysis & 95.9 & 97.7 & 95.0 & $<0.001$ \\
\hline Peritoneal dialysis & 4.1 & 2.3 & 5.0 & \\
\hline \multicolumn{5}{|l|}{ Hemodialysis access, \% } \\
\hline AV access & 17.7 & 9.1 & 21.6 & $<0.001$ \\
\hline Central venous catheter & 82.3 & 90.9 & 78.4 & \\
\hline Maturing AV access (among CVC) & 21.4 & 15.1 & 24.7 & $<0.001$ \\
\hline
\end{tabular}


Table 2 Characteristics of patients who initiated dialysis in 2008 stratified by 1-year mortality (Continued)

\begin{tabular}{|c|c|c|c|c|}
\hline Variable & All & Death $\leq 1$ year & Death $>1$ year & $P$ value \\
\hline \multicolumn{5}{|c|}{ Laboratory variables from within 45-day period prior to most recent ESRD episode } \\
\hline Albumin, $\mathrm{g} / \mathrm{dL}$ & $3.1(0.7)$ & $3.0(0.7)$ & $3.2(0.7)$ & $<0.001$ \\
\hline$<3.5$ & 51.8 & 57.6 & 49.1 & \\
\hline$\geq 3.5$ & 25.3 & 18.4 & 28.4 & $<0.001$ \\
\hline Missing & 23.0 & 24.0 & 22.5 & \\
\hline Hemoglobin, g/dL & $10.0(1.5)$ & $10.0(1.5)$ & $10.1(1.5)$ & \\
\hline$<11$ & 68.3 & 69.1 & 67.9 & \\
\hline $11-12$ & 15.1 & 13.9 & 15.7 & \\
\hline$>12$ & 8.5 & 8.3 & 8.6 & 0.05 \\
\hline Missing & 8.1 & 8.7 & 7.8 & $<0.001$ \\
\hline \multicolumn{5}{|l|}{ Dialysis setting, \% } \\
\hline Dialysis facility & 95.0 & 96.2 & 94.5 & $<0.001$ \\
\hline Home & 4.3 & 2.5 & 5.1 & \\
\hline Skilled nursing facility & 0.7 & 1.3 & 0.5 & \\
\hline \multicolumn{5}{|l|}{ Employment status, \% } \\
\hline Unemployed & 11.1 & 10.2 & 11.5 & $<0.001$ \\
\hline Employed + others & 5.9 & 4.7 & 6.4 & \\
\hline Retired-age & 61.6 & 68.3 & 58.5 & \\
\hline Retired-disability & 21.4 & 16.7 & 23.5 & \\
\hline \multicolumn{5}{|c|}{ Acute hospitalization during 2 year Pre-ESRD } \\
\hline Frequency, \% & 88.9 & 93.4 & 86.9 & $<0.001$ \\
\hline Total length of stay (days) & $23.3(27.9)$ & $31.1(32.3)$ & $19.7(24.9)$ & $<0.001$ \\
\hline \multicolumn{5}{|l|}{ Pre-dialysis nephrology care, \% } \\
\hline None & 27.8 & 35.0 & 24.5 & $<0.001$ \\
\hline$<12$ months & 33.0 & 29.3 & 34.8 & \\
\hline$>12$ months & 26.3 & 20.0 & 29.2 & \\
\hline Unknown & 12.8 & 15.7 & 11.5 & \\
\hline \multicolumn{5}{|l|}{ Cause of end stage renal disease, $\%$} \\
\hline Diabetes mellitus & 45.9 & 40.8 & 48.3 & $<0.001$ \\
\hline Hypertension/LVD & 32.3 & 34.1 & 31.5 & \\
\hline Malignancy & 2.6 & 4.2 & 1.9 & \\
\hline Cystic/hereditary & 1.3 & 0.7 & 1.5 & \\
\hline Secondary GN/vasculits & 1.2 & 1.1 & 1.3 & \\
\hline Glomerulonephritis & 3.9 & 2.8 & 4.4 & \\
\hline Interstitial nephritis/pyelonephritis & 2.9 & 2.9 & 2.8 & \\
\hline Others & 9.8 & 13.3 & 8.2 & \\
\hline History of nursing home, $\%$ & 10.3 & 18.0 & 6.8 & $<0.001$ \\
\hline Provision of transplant information, \% & 65.6 & 57.9 & 69.1 & $<0.001$ \\
\hline
\end{tabular}

Data are presented in mean (SD), or proportion where appropriate. CVA/TIA cerebrovascular accident/transient ischemic attack, COPD chronic obstructive pulmonary disease, $A V$ arteriovenous, CVC central venous catheter, $L V D$ large vessel disease, GN glomerulonephritis

regards to comorbidities, $56.2 \%$ had diabetes, $85.2 \%$ had hypertension, $42.9 \%$ had atherosclerotic heart disease, $9.8 \%$ had history of malignancy, 3.5\% had history of amputation, $18.1 \%$ had peripheral vascular disease, and $12.4 \%$ has history of transient ischemic attack/ cerebrovascular accident. $34.4 \%$ did not report being informed about kidney transplant options prior to initiating dialysis. Only $4.1 \%$ of patients initiated PD. 
Majority, 95\% used dialysis facility as dialysis setting. Of those who started hemodialysis, $82.3 \%$ initiated with a CVC and the remaining $17.7 \%$ initiated with an AV access. Among pre-dialysis clinical factors, $51.8 \%$ had low serum albumin <3.5 mg/dl, $68.3 \%$ had low hemoglobin $<11 \mathrm{~g} / \mathrm{dl}, 88.9 \%$ had at least 1 hospitalization in the 2 years prior to initiation of dialysis, $10.3 \%$ had a history of a nursing home stay, and $27.8 \%$ had not seen a nephrologist prior to starting dialysis.

At dialysis initiation, $18.7 \%$ of patients were reported to have history of poor functional status. Patients with poor functional status were more likely to be octogenarians $(31.9 \%$ vs. $24.2 \%, p<0.001)$, females $(51.2 \%$ vs. $44.1 \%$, $p<0.001)$, and nursing home residents $(38.2 \%$ vs. $3.9 \%$, $p<0.001)$. Patient with poor functional status also had higher rates of other comorbidities, and low serum hemoglobin $(71.8 \%$ vs. $67.5 \%, p<0.001)$ or low serum albumin $(60.5 \%$ vs. $49.7 \%, p<0.001)$. Furthermore, patients with poor functional status were provided with lower frequency of transplant information prior to initiating dialysis $(55.5 \%$ vs. $67.9 \%, p<0.001)$. Examination of pre-dialysis clinical factors revealed that higher frequency of patients with poor functional status initiated dialysis without any prior nephrology care $(35.3 \%$ vs. $26.1 \%, p<0.001)$. Pre-dialysis hospitalizations were associated with poor functional status (93.8\% vs. $87.8 \%, p<0.001)$. Furthermore, total hospital days stay during 2-year pre-dialysis hospitalizations was longer in patients with poor functional status (35.6 days vs. 20.4 days, $p<0.001$ ).

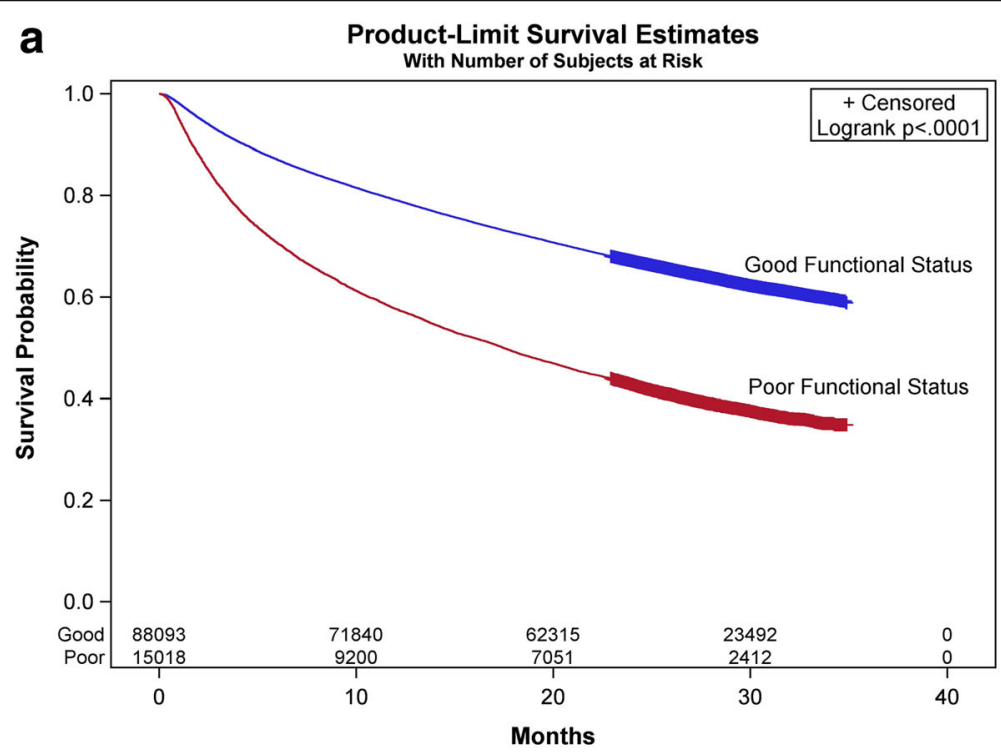

b Product-Limit Survival Estimates

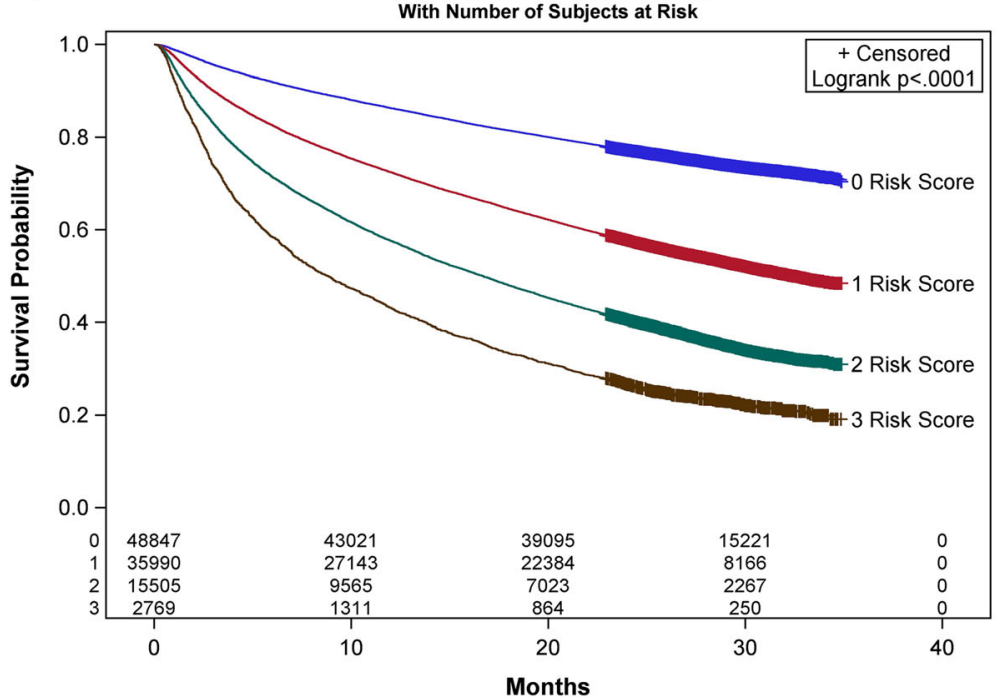

Fig. 2 Kaplan-Meier survival curves by end stage renal disease to death in dialysis patients by (a) functional status, and (b) risk score levels 


\section{Primary and secondary outcomes}

Overall, 1-year all cause mortality was $31.2 \%$ and 90 -day mortality was $11.6 \%$. Among the deceased patients, death from a cardiovascular cause (38.2\%) and withdrawal of dialysis (11.6\%) were the most common causes of death. Patients with poor functional status had higher unadjusted one-year mortality than those with good functional status $(46.4 \%$ vs. $27.7 \%, p<0.001)$. Table 2 shows the patient characteristics associated with 1-year mortality. Patients with one-year mortality more frequently lacked pre-ESRD nephrology care ( $35 \%$ vs. $24.5 \%$, $p<0.001)$, resided more often in a nursing home ( $18 \%$ vs. $6.8 \%, p<0.001)$, had higher rates of pre-dialysis hospitalization $(93.4 \%$ vs. $86.9 \%, p<0.001)$ and were less likely to be provided with transplant information $(57.9 \%$ vs. $69.1 \%, p<0.001)$.

Figure 2a shows Kaplan-Meier survival curves comparing patients with and without poor functional status. In this time-to-event analysis, poor functional status was associated with lower survival (log-rank test $p<0.0001$ ). Figure $2 \mathrm{~b}$ represents Kaplan-Meier survival analysis based on level of the risk scores depending on absence or presence of poor functional status, octogenarian status and pre-ESRD hospitalizations (log rank test $p<0.0001)$. Oneyear mortality at the different levels of our risk score was $14 \%, 26 \%, 42 \%$, and $57 \%$ for scores of $0,1,2$, and 3 respectively. Figure 3 shows rates of one-year mortality among those with poor functional status by octogenarian status, pre-dialysis nephrology care and acute care hospitalization. Of note, octogenarians with poor functional status had 1-year mortality rate of $57 \%$ compared to $42 \%$ in those less than 80 years of age ( $p$ value $<0.001$ ). However, the interaction between poor functional status and octogenarians for the outcome of one-year mortality in patients with ESRD was not significant $(p=0.15)$. By multivariate analysis, one-year adjusted mortality

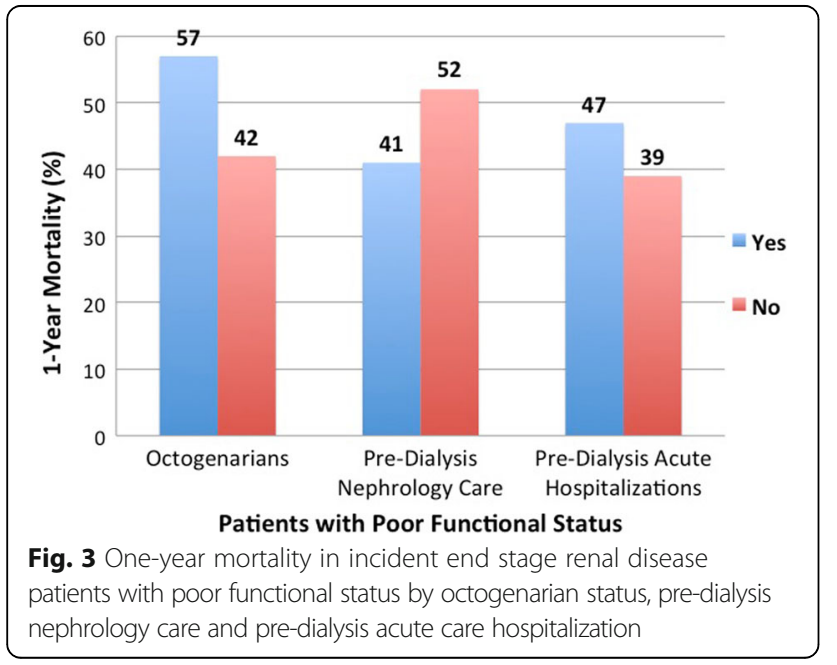

was higher in patients with poor functional status (odds ratio $[\mathrm{OR}], 1.48$; 95\% confidence interval $[\mathrm{CI}], 1.40-1.57)$ (Table 3). In Cox proportional hazard model (Additional file 1), $51.3 \%$ of the study cohort patients died during a mean follow up period of $21.7 \pm 10.6$ months; and poor functional status was associated with higher risk of death (hazard ratio [HR], 1.28 (1.24-1.33), $p<0.001$ ).

For the outcome of dialysis modality, patients with poor functional status had higher use of hemodialysis as the initial dialysis modality than those with good functional status $(98.4 \%$ vs. $95.3 \%, p<0.001)$, an association that was maintained in the adjusted models (OR, 1.39; 95\% CI, 1.16-1.66 (Table 4). Among those that initiated hemodialysis with CVC, poor functional status was associated with lower rates of maturing AV access (15.1\% vs. $24.7 \%, \mathrm{p}<0.001)$. AV access was the less frequently used hemodialysis access in those with poor functional status $(10.7 \%$ vs. $19.3 \%, p<0.001)$. In adjusted analyses, patients with poor functional status had lower odds of initiating dialysis with $\mathrm{AV}$ access than patients with good functional status (OR, 0.79; CI, 0.72-0.86) (Table 5). Figure 4 shows the association of poor functional status with outcomes of 1-year mortality, type of dialysis modality, and type of vascular access for hemodialysis initiation.

\section{Discussion}

In this national sample, we found that one-in-five patients who initiated dialysis did so with poor functional status, and when present and after taking pre-dialysis health into account, it was associated with higher mortality, lower likelihood of PD and greater use of CVC for hemodialysis initiation. To our knowledge, this is among the first reports to have examined the effect of functional status and pre-dialysis health status including predialysis hospitalizations on long-term dialysis outcomes among older adults in United States.

There is a high prevalence of disability in elderly hemodialysis patients and observational studies have reported higher mortality with poor functional status in established dialysis patients $[14,15]$. Kurella et al. studied the trajectory of functional status before and after the initiation of dialysis among elderly nursing home residents with ESRD. The authors concluded that initiation of dialysis in elderly nursing home residents was associated with substantial decline in functional status and worsening quality of life, with more than half dying at 1-year after dialysis initiation [6]. In another study, severely and moderately impaired functional status was significantly associated with early death after initiating dialysis (adjusted risk ratios: 3.93 and 2.38, respectively) [15]. However, none of these studies took into account pre-dialysis health status and health care prior to dialysis initiation.

The elderly CKD population in United States has a unique medical and social profile, and represents the 
Table 3 Independent variable predictors of 1-year mortality in incident end stage renal disease patients in the final regression model

\begin{tabular}{|c|c|}
\hline Variable $^{a}$ & Odds ratio $(95 \%$ \\
\hline Poor functional status & $1.48(1.40,1.56)$ \\
\hline \multicolumn{2}{|l|}{ Dialysis access } \\
\hline Central venous catheter & $1.84(1.72,1.97)$ \\
\hline Peritoneal dialysis & $1.24(1.08,1.42)$ \\
\hline Age $\geq 80$ years & $1.65(1.57,1.73)$ \\
\hline \multicolumn{2}{|l|}{ Body mass index, $\mathrm{kg} / \mathrm{m}^{2}$} \\
\hline$<18.5$ & $1.82(1.64,2.03)$ \\
\hline $18.5-25$ & $1.34(1.27,1.41)$ \\
\hline $25-30$ & $1.10(1.04,1.16)$ \\
\hline Missing & $1.19(1.01,1.40)$ \\
\hline Females & $0.94(0.91,0.99)$ \\
\hline \multicolumn{2}{|l|}{ Race } \\
\hline Asians & $0.63(0.55,0.71)$ \\
\hline Blacks & $0.68(0.65,0.72)$ \\
\hline Hispanics & $0.65(0.60,0.70)$ \\
\hline Native Americans & $0.83(0.67,1.03)$ \\
\hline History of nursing home & $1.80(1.67,1.92)$ \\
\hline Unemployment & $1.04(0.98,1.12)$ \\
\hline \multicolumn{2}{|l|}{ Comorbidities } \\
\hline Congestive heart failure & $1.37(1.32,1.44)$ \\
\hline Atherosclerotic heart disease & $1.11(1.07,1.16)$ \\
\hline Hypertension/large vessel disease & $0.72(0.68,0.77)$ \\
\hline Diabetes mellitus & $0.97(0.92,1.03)$ \\
\hline Cancer & $1.27(1.19,1.36)$ \\
\hline Amputation & $0.98(0.88,1.10)$ \\
\hline Peripheral vascular disease & $1.10(1.04,1.16)$ \\
\hline CVA/TIA & $1.06(1.00,1.13)$ \\
\hline Chronic obstructive pulmonary disease & $1.29(1.22,1.37)$ \\
\hline \multicolumn{2}{|l|}{ Albumin, g/dL } \\
\hline$<3.5$ & $1.42(1.35,1.50)$ \\
\hline Missing & $1.33(1.25,1.41)$ \\
\hline \multicolumn{2}{|l|}{ Hemoglobin, g/dL } \\
\hline$<11$ & $0.93(0.87,1.01)$ \\
\hline $11-12$ & $0.90(0.83,0.99)$ \\
\hline Missing & $1.06(0.96,1.17)$ \\
\hline Pre-dialysis acute hospitalization & $1.31(1.21,1.42)$ \\
\hline \multicolumn{2}{|l|}{ Cause of ESRD } \\
\hline Cystic/hereditary & $0.71(0.57,0.88)$ \\
\hline Glomerulonephritis & $0.76(0.68,0.86)$ \\
\hline Hypertension/large vessel disease & $1.08(1.02,1.14)$ \\
\hline Interstitial nephritis/pyelonephritis & $0.97(0.85,1.10)$ \\
\hline Others/unknown & $1.26(1.17,1.36)$ \\
\hline
\end{tabular}

Table 3 Independent variable predictors of 1-year mortality in incident end stage renal disease patients in the final regression model (Continued)

\begin{tabular}{ll}
\hline Variable $^{\mathrm{a}}$ & Odds ratio $(95 \% \mathrm{Cl})$ \\
\hline Malignancy & $2.07(1.82,2.35)$ \\
Vasculits/secondary GN & $0.96(0.79,1.16)$ \\
Pre-dialysis nephrology care & \\
$0-12$ months & $0.78(0.74,0.82)$ \\
$>12$ months & $0.70(0.66,0.74)$ \\
Unknown & $1.05(0.99,1.12)$ \\
Access to transplant information & $0.81(0.77,0.84)$
\end{tabular}

ESRD end stage renal disease, CVA/TIA cerebrovascular accident/transient ischemic attack, GN glomerulonephritis

${ }^{a}$ Referents were good functional status to poor functional status, arteriovenous access for vascular access, $>30$ for body mass index, male for females, White for race, no for comorbidities, $>3.5 \mathrm{mg} / \mathrm{dl}$ for serum albumin, $>12$ for serum hemoglobin,, and diabetes mellitus for ESRD cause

fastest growing population in Unites States with ESRD [10]. Elderly patients initiating dialysis have a high prevalence of comorbidities that is associated with poor survival [16]. Pre-dialysis hospitalizations and lack of pre-ESRD nephrology care can further impact long-term outcomes in them [17]. Some retrospective studies have looked at the impact of pre-dialysis factors in isolation on mortality among older adults. In a German hemodialysis center, later referral to a nephrologist was associated with 1.8 fold increase in mortality in those over 75 years of age [18]. Crews et al. studied the association of pre-dialysis health status with focus on timing of dialysis initiation among older adults in United States. They concluded that early initiators were more likely to have all cause hospitalization days preceding dialysis initiation; and that early dialysis initiation did not benefit patients with functional limitation [12]. The present study is unique since it examined the impact of poor functional status at dialysis initiation along with pre-dialysis health status on post dialysis outcomes. In our study, one-fifth of the elderly patients were reported to have poor functional status at the time of dialysis initiation and by the end of 12 months, about onethird of them had died. Older patients with poor functional status were also associated with higher odds of predialysis hospitalizations, and were less likely to receive nephrology care prior to initiation dialysis.

Concerns surrounding poor functional status are complex, and are difficult to modify once dialysis begins [6]. Functional status and comorbid disease burden in elderly patients with advanced chronic kidney disease referred for pre-dialysis education are independent predictors of mortality $[8,19]$. Our analysis allows the opportunity to consider functional status prior to dialysis initiation along with pre-dialysis health status. To that effect, we specifically looked at the risk factors of lack of pre-dialysis nephrology care, presence of 
Table 4 Independent variable predictors of hemodialysis vs. peritoneal dialysis as the dialysis modality in the final regression model

\begin{tabular}{|c|c|}
\hline Variable $^{a}$ & Odds ratio $(95 \%$ \\
\hline Poor functional status & $1.39(1.16,1.66)$ \\
\hline Age $\geq 80$ years & $1.70(1.50,1.94)$ \\
\hline \multicolumn{2}{|l|}{ Body mass index, $\mathrm{kg} / \mathrm{m}^{2}$} \\
\hline$<18.5$ & $0.92(0.81,1.04)$ \\
\hline $18.5-25$ & $0.85(0.76,0.96)$ \\
\hline $25-30$ & $1.27(0.93,1.75)$ \\
\hline Missing & $0.88(0.60,1.29)$ \\
\hline Females & $0.93(0.85,1.02)$ \\
\hline \multicolumn{2}{|l|}{ Race } \\
\hline Asians & $1.15(0.90,1.48)$ \\
\hline Blacks & $1.88(1.65,2.14)$ \\
\hline Hispanics & $1.56(1.30,1.88)$ \\
\hline Native Americans & $0.94(0.60,1.45)$ \\
\hline History of nursing home & $3.86(2.54,5.85)$ \\
\hline Unemployment & $1.09(0.93,1.28)$ \\
\hline \multicolumn{2}{|l|}{ Comorbidities } \\
\hline Congestive heart failure & $1.35(1.21,1.51)$ \\
\hline Atherosclerotic heart disease & $1.01(0.91,1.12)$ \\
\hline Hypertension & $0.96(0.84,1.11)$ \\
\hline Diabetes mellitus & $0.97(0.86,1.11)$ \\
\hline Cancer & $1.01(0.86,1.89)$ \\
\hline Peripheral vascular disease & $1.08(0.95,1.24)$ \\
\hline CVA/TIA & $0.95(0.81,1.10)$ \\
\hline Chronic obstructive pulmonary disease & $1.40(1.18,1.67)$ \\
\hline \multicolumn{2}{|l|}{ Albumin, g/dL } \\
\hline$<3.5$ & $2.15(1.93,2.40)$ \\
\hline Missing & $1.42(1.25,1.61)$ \\
\hline \multicolumn{2}{|l|}{ Hemoglobin, g/dL } \\
\hline$<11$ & $1.86(1.63,2.14)$ \\
\hline $11-12$ & $1.16(0.99,1.36)$ \\
\hline Missing & $1.49(1.21,1.83)$ \\
\hline Pre-dialysis acute hospitalization & $2.61(2.35,2.90)$ \\
\hline \multicolumn{2}{|l|}{ Cause of ESRD } \\
\hline Cystic/hereditary & $0.82(0.61,1.10)$ \\
\hline Glomerulonephritis & $0.61(0.50,0.75)$ \\
\hline Hypertension/large vessel disease & $0.92(0.80,1.05)$ \\
\hline Interstitial nephritis/pyelonephritis & $1.19(0.88,1.60)$ \\
\hline Others/unknown & $1.15(0.92,1.43)$ \\
\hline Malignancy & $1.05(0.75,1.47)$ \\
\hline Vasculits/secondary GN & $0.83(0.55,1.25)$ \\
\hline
\end{tabular}

Table 4 Independent variable predictors of hemodialysis vs. peritoneal dialysis as the dialysis modality in the final regression model (Continued)

\begin{tabular}{ll}
\hline Variable $^{\mathrm{a}}$ & Odds ratio $(95 \% \mathrm{Cl})$ \\
\hline Pre-dialysis nephrology care & \\
0-12 months & $0.23(0.19,0.28)$ \\
$>12$ months & $0.23(0.19,0.28)$ \\
Unknown & $0.67(0.52,0.88)$ \\
Access to transplant information & $0.50(0.44,0.56)$ \\
\hline
\end{tabular}

ESRD end stage renal disease, CVA/TIA cerebrovascular accident/transient ischemic attack, GN glomerulonephritis

${ }^{a}$ Referents were good functional status to poor functional status, $>30$ for body mass index, White for race, males for females, no for comorbidities,

$>3.5 \mathrm{mg} / \mathrm{dl}$ for serum albumin, > 12 for serum hemoglobin, and diabetes mellitus for ESRD cause

pre-dialysis acute care hospitalizations, comorbidities, and octogenarian status. This information on clinical outcomes in elderly dialysis patients becomes very important, since pre-dialysis health status is usually not taken into account when older adults are initiated on dialysis. Thamer et al. developed a shared decision making tool for nephrologists and patients to estimate the risk of early mortality following initiation of dialysis. Older age, low albumin, assistance with daily activities, nursing home history, comorbidities of cancer and heart failure; and hospitalizations prior to initiating dialysis were the 7 significant predictors of mortality. However, using their model, which was different from ours, mortality could only be predicted at 3 months and 6 months but not at 1 year [4]. Our study concludes that poor functional status in elderly dialysis patients, when adjusted for lack of pre-dialysis nephrology care, predialysis acute hospitalizations, comorbidities and other covariates has a significant impact on 1-year mortality; and increases the risk of dying within 1 year by $48 \%$. It therefore becomes imperative for clinicians to incorporate screening strategies for functional impairment with their routine plan of care. Patients who are identified to be at risk for functional decline may benefit from referral to a geriatrician, interdisciplinary care and physical rehabilitation [20]. Future prospective studies are, however, required to study the impact of the physical rehabilitation on long-term outcomes in elderly dialysis patients.

Several retrospective studies have evaluated vascular access outcomes in the elderly, but none of them have taken functional status and pre-dialysis health into account $[21,22]$. Xue et al. reported that more than half of elderly patients had CVC at dialysis initiation with hazard ratio of 1.7 for 1-year mortality as compared to those with AVF [23]. In our study, more than two thirds of elderly patients started hemodialysis with a CVC; and had 35\% chance of dying before 1 year. Additionally, patients with poor functional status who used CVC for hemodialysis initiation had 1-year mortality of $49 \%$. 
Table $\mathbf{5}$ Independent variable predictors of arteriovenous access vs. central venous catheter as the vascular access for hemodialysis initiation in the final regression model

\begin{tabular}{|c|c|}
\hline Variable $^{a}$ & Odds ratio $(95 \%$ \\
\hline Poor functional status & $0.79(0.72,0.86)$ \\
\hline Age $\geq 80$ years & $0.88(0.82,0.93)$ \\
\hline \multicolumn{2}{|l|}{ Body mass index, $\mathrm{kg} / \mathrm{m}^{2}$} \\
\hline$<18.5$ & $0.96(0.82,1.11)$ \\
\hline $18.5-25$ & $0.97(0.91,1.04)$ \\
\hline $25-30$ & $1.03(0.96,1.10)$ \\
\hline Missing & $1.02(0.83,1.27)$ \\
\hline Females & $0.83(0.79,0.88)$ \\
\hline \multicolumn{2}{|l|}{ Race } \\
\hline Asians & $0.94(0.81,1.10)$ \\
\hline Blacks & $1.10(1.03,1.17)$ \\
\hline Hispanics & $0.81(0.74,0.90)$ \\
\hline Native Americans & $0.88(0.67,1.17)$ \\
\hline History of nursing home & $0.71(0.63,0.80)$ \\
\hline Unemployment & $1.06(0.98,1.16)$ \\
\hline \multicolumn{2}{|l|}{ Comorbidities } \\
\hline Congestive heart failure & $0.75(0.71,0.80)$ \\
\hline Atherosclerotic heart disease & $0.92(0.87,0.97)$ \\
\hline Hypertension & $1.18(1.09,1.28)$ \\
\hline Diabetes mellitus & $0.96(0.89,1.03)$ \\
\hline Cancer & $0.97(0.87,1.06)$ \\
\hline Amputation & $0.88(0.75,1.03)$ \\
\hline Peripheral vascular disease & $1.02(0.95,1.09)$ \\
\hline CVA/TIA & $1.36(0.95,1.12)$ \\
\hline Chronic obstructive pulmonary disease & $0.87(0.79,0.94)$ \\
\hline \multicolumn{2}{|l|}{ Albumin, g/dL } \\
\hline$<3.5$ & $0.52(0.49,0.55)$ \\
\hline Missing & $0.58(0.54,0.63)$ \\
\hline \multicolumn{2}{|l|}{ Hemoglobin, g/dL } \\
\hline$<11$ & $0.87(0.79,0.95)$ \\
\hline $11-12$ & $1.18(1.06,1.31)$ \\
\hline Missing & $0.99(0.87,1.12)$ \\
\hline Pre-dialysis acute hospitalization & $0.41(0.38,0.44)$ \\
\hline \multicolumn{2}{|l|}{ Cause of ESRD } \\
\hline Cystic/hereditary & $1.40(1.11,1.66)$ \\
\hline Glomerulonephritis & $0.93(0.82,1.07)$ \\
\hline Hypertension/large vessel disease & $0.88(0.82,0.95)$ \\
\hline Interstitial nephritis/pyelonephritis & $0.83(0.70,0.98)$ \\
\hline Others/unknown & $0.52(0.45,0.59)$ \\
\hline Malignancy & $0.56(0.46,0.69)$ \\
\hline Vasculits/secondary GN & $0.52(0.39,0.70)$ \\
\hline
\end{tabular}

Table $\mathbf{5}$ Independent variable predictors of arteriovenous access vs. central venous catheter as the vascular access for hemodialysis initiation in the final regression model (Continued)

\begin{tabular}{ll}
\hline Variable $^{a}$ & Odds ratio $(95 \% \mathrm{Cl})$ \\
\hline Pre-dialysis nephrology care & \\
$0-12$ months & $6.49(5.86,7.19)$ \\
$>12$ months & $11.42(10.31,12.65)$ \\
Unknown & $1.77(1.54,2.04)$ \\
Access to transplant information & $1.18(1.12,1.25)$
\end{tabular}

ESRD end stage renal disease, CVA/TIA cerebrovascular accident/transient ischemic attack, GN glomerulonephritis

${ }^{a}$ Referents were good functional status to poor functional status, arteriovenous access for vascular access, $>30$ for body mass index, male for gender, White for race, no for comorbidities, $>3.5 \mathrm{mg} / \mathrm{dl}$ for serum albumin,

$>12$ for serum hemoglobin,, and diabetes mellitus for ESRD cause

While there are no uniform guidelines for access planning in the patients over 60-years of age, functional status prior to dialysis and not age alone may need to be considered in guiding our decisions regarding ideal vascular access placement in elderly patients. Observational studies have reported similar survival and quality of life in elderly patients undergoing hemodialysis vs. peritoneal dialysis [24, 25]. Even though, peritoneal dialysis modality may be a better option in elderly patients due to lack of vascular access, gentle ultrafiltration and ease of performing at home; its use may be limited among those with poor functional status $[25,26]$. With assistance required in the daily activities, it may be therefore more appropriate for elderly ESRD patients with poor functional to be initiated on hemodialysis than peritoneal dialysis; and utilize CVC than AV access for hemodialysis initiation, similar to the findings seen in the present study.

Our study has limitations. Observational study and administrative information limit the information to be associative and cannot establish causality. Data from USRDS used for the study was 10 years old and there is a possibility of changes in the patient characteristics and patient care over the subsequent years. However, our report utilizes the information from the largest administrative database for dialysis patients that are maintained prospectively in United States. Functional status was defined by the reporting of physicians on form 2728, which can introduce misclassification bias and recall bias. Even though characterization of functional status occurred only once during initiation of dialysis in form 2728 , and could change over time, this may provide physicians a quick assessment of individual's ability to do activities of daily living. To the best of our knowledge, functional status as defined from form 2728 has not been validated, and remains another limitation of the administrative data. Comorbidities were also determined from form 2718 , and even though it may be a better way to assess chronic conditions in ESRD patients, it was not possible to corroborate the information provided by the physician 


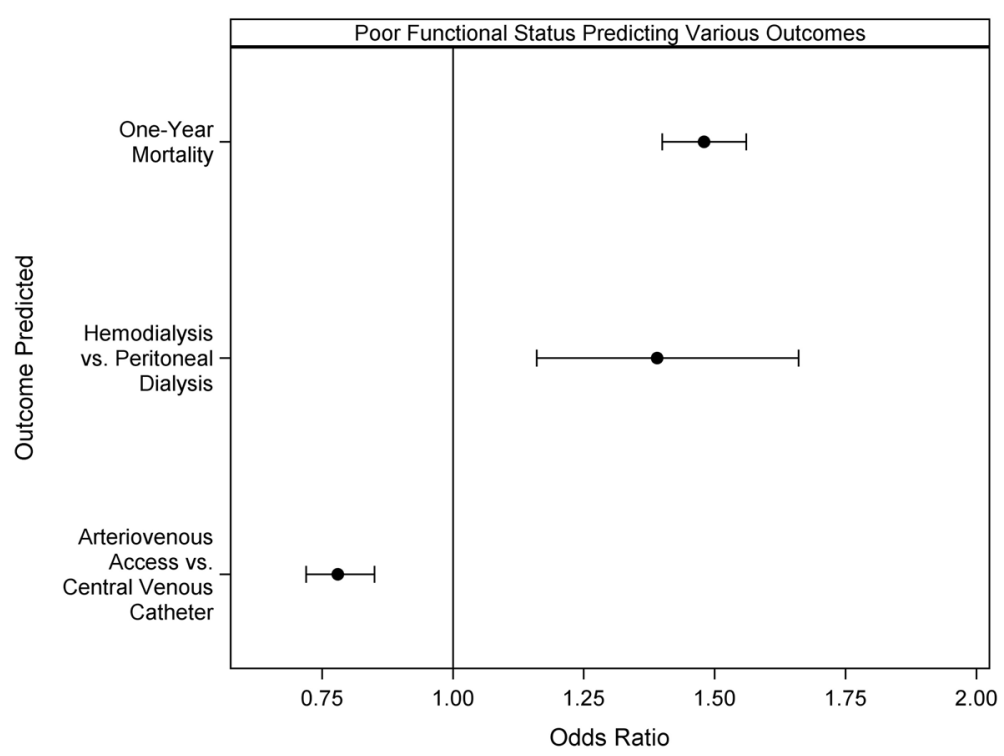

Fig. 4 Association of poor functional status with outcomes of one-year mortality, type of dialysis modality (hemodialysis vs. peritoneal dialysis), and type of vascular access (arteriovenous access vs. central venous catheter) for hemodialysis initiation

to patient-level information derived from medical records, and this validation gap remains another limitation. Additionally, individual level variables, including educational level and socioeconomic, that are not captured on form 2728 could be other predictors of interest and were not available for our analysis. Yet, by using the linked Medicare files, we were able to account for factors at the time of dialysis initiation as well as pre-dialysis health status in determining 1-year mortality.

Future directions include developing a decision making tool based on functional status and pre-dialysis health for patients initiating dialysis, which could guide both patients and physicians in shared decision making and conservative care options if appropriate. High quality studies are needed to examine comparative outcomes of conservative care and renal replacement modalities among elderly patients with poor functional status.

\section{Conclusion}

Our findings indicate that poor functional status at the time of dialysis initiation is associated with significantly high 1-year mortality among elderly dialysis patients. Poor functional status also increases the risk of infacility hemodialysis, and lack of arteriovenous access. Pre-dialysis health significantly impact clinical outcomes in elderly dialysis patients with poor functional status. In elderly patients with a large number of comorbidities, functional impairment and poor pre-dialysis health, a discussion regarding using conservative management or a time limited trial of hemodialysis may be appropriate. The information from the present study can influence health care provider's decision to initiate dialysis, help counsel patients and families, and can facilitate an integrated approach in shared decision-making. Whether strategies to improve functional status in advanced stages of CKD would improve long-term clinical outcomes needs further investigation.

\section{Additional file}

Additional file 1: Independent risk factors of mortality in incident end stage renal disease patients in the Cox proportional model. (DOCX $84 \mathrm{~kb}$ )

\section{Abbreviations}

ASHD: Atherosclerotic heart disease; AV: Arteriovenous; CHF: Congestive heart failure; Cl: Confidence interval; CKD: Chronic kidney disease;

COPD: Chronic obstructive pulmonary disease; CVA/TIA: Cerebrovascular accident/transient ischemic attack; ESRD: End stage renal disease;

GN: Glomerulonephritis; LVD: Large vessel disease; OR: Odds ratio; PD: Peritoneal dialysis; SD: Standard deviation; USRDS: United States renal data system

\section{Acknowledgements}

The authors would like to thank Annette Christianson for her help with the manuscript figures. Silvi Shah is supported by a Junior Pilot Faculty Award from University of Cincinnati's Department of Internal Medicine.

\section{Funding}

Silvi Shah is supported by a Junior Pilot Faculty Award from University of Cincinnati's Department of Internal Medicine.

\section{Availability of data and materials}

The datasets used and/or analysed during the current study are available from the corresponding author on reasonable request.

\section{Authors' contributions}

SS initiated the study, designed the study and wrote the initial manuscript. $\mathrm{AL}$ analyzed and interpreted the data, contributed to the study design and manuscript review. CT assisted SS with study design and implementation, revision of the manuscript and did the final approval of the manuscript. All authors reviewed the manuscript. 


\section{Ethics approval and consent to participate}

The data was obtained by a formal request to USRDS. The USRDS required the institutional review board to review the request, and the study was deemed exempt by University of Cincinnati institutional review board.

\section{Competing interests}

All the authors have no disclosures and competing interests. The results presented in this paper have not been published previously in whole or part except in abstract format.

\section{Publisher's Note}

Springer Nature remains neutral with regard to jurisdictional claims in published maps and institutional affiliations.

\section{Author details}

'Division of Nephrology and Hypertension, University of Cincinnati, 231 Albert Sabin Way, Cincinnati, OH 45267, USA. ²Department of Family and Community Medicine, University of Cincinnati, Cincinnati, OH, USA. ${ }^{3}$ Division of Nephrology, University of Cincinnati and VA Medical Center, Cincinnati, Ohio, USA.

Received: 27 January 2018 Accepted: 15 April 2018

Published online: 27 April 2018

\section{References}

1. U.S. Renal Data System. Researcher's guide to the USRDS database, vol. 2015. Bethesda, MD: National Institutes of Health, National Institute of Diabetes and Digestive and Kidney Diseases; 2015.

2. Noordzij M, Jager KJ. Increased mortality early after dialysis initiation: a universal phenomenon. Kidney Int. 2014;85(1):12-4.

3. Soucie JM, McClellan WM. Early death in dialysis patients: risk factors and impact on incidence and mortality rates. J Am Soc Nephrol. 1996;7(10): 2169-75.

4. Thamer M, Kaufman JS, Zhang Y, Zhang Q, Cotter DJ, Bang H. Predicting early death among elderly Dialysis patients: development and validation of a risk score to assist shared decision making for Dialysis initiation. Am J Kidney Dis. 2015;66(6):1024-32.

5. Bao Y, Dalrymple L, Chertow GM, Kaysen GA, Johansen KL. Frailty, dialysis initiation, and mortality in end-stage renal disease. Arch Intern Med. 2012; 172(14):1071-7.

6. Kurella Tamura M, Covinsky KE, Chertow GM, Yaffe K, Landefeld CS, McCulloch CE. Functional status of elderly adults before and after initiation of dialysis. N Engl J Med. 2009;361(16):1539-47.

7. Leidy NK. Functional status and the forward progress of merry-go-rounds: toward a coherent analytical framework. Nurs Res. 1994;43(4):196-202.

8. Ritchie JP, Alderson H, Green D, Chiu D, Sinha S, Middleton R, O'Donoghue D, Kalra PA. Functional status and mortality in chronic kidney disease: results from a prospective observational study. Nephron Clin Pract. 2014;128(1-2):22-8.

9. Fraser SD, Roderick PJ, May CR, McIntyre N, Mclntyre C, Fluck RJ, Shardlow A, Taal MW. The burden of comorbidity in people with chronic kidney disease stage 3: a cohort study. BMC Nephrol. 2015;16:193.

10. United States Renal Data System. USRDS annual data report: epidemiology of kidney disease in the United States. Bethesda, MD: National Institutes of Health National Institute of Diabetes and Digestive and Kidney Disease; 2016.

11. Daratha KB, Short RA, Corbett CF, Ring ME, Alicic R, Choka R, Tuttle KR. Risks of subsequent hospitalization and death in patients with kidney disease. Clin J Am Soc Nephrol. 2012;7(3):409-16.

12. Crews DC, Scialla JJ, Liu J, Guo H, Bandeen-Roche K, Ephraim PL, Jaar BG, Sozio SM, Miskulin DC, Tangri N, et al. Predialysis health, dialysis timing, and outcomes among older United States adults. J Am Soc Nephrol. 2014;25(2):370-9.

13. Kausz AT, Obrador GT, Arora P, Ruthazer R, Levey AS, Pereira BJ. Late initiation of dialysis among women and ethnic minorities in the United States. J Am Soc Nephrol. 2000;11(12):2351-7.

14. Cook WL, Jassal SV. Functional dependencies among the elderly on hemodialysis. Kidney Int. 2008;73(11):1289-95.

15. Yazawa M, Kido R, Ohira S, Hasegawa T, Hanafusa N, Iseki K, Tsubakihara Y, Shibagaki $Y$. Early mortality was highly and strongly associated with functional status in incident Japanese hemodialysis patients: a cohort study of the large National Dialysis Registry. PLoS One. 2016;11(6):e0156951.
16. Foote C, Ninomiya T, Gallagher M, Perkovic V, Cass A, McDonald SP, Jardine M. Survival of elderly dialysis patients is predicted by both patient and practice characteristics. Nephrol Dial Transplant. 2012;27(9):3581-7.

17. Baek SH, Ahn S, Lee SW, Park YS, Kim S, Na KY, Chae DW, Kim S, Chin HJ. Outcomes of predialysis nephrology care in elderly patients beginning to undergo dialysis. PLoS One. 2015;10(6):e0128715.

18. Schwenger V, Morath C, Hofmann A, Hoffmann O, Zeier M, Ritz E. Late referral-a major cause of poor outcome in the very elderly dialysis patient. Nephrol Dial Transplant. 2006;21(4):962-7.

19. Pugh J, Aggett J, Goodland A, Prichard A, Thomas N, Donovan K, Roberts G. Frailty and comorbidity are independent predictors of outcome in patients referred for pre-dialysis education. Clin Kidney J. 2016;9(2):324-9.

20. Cohen HJ, Feussner JR, Weinberger M, Carnes M, Hamdy RC, Hsieh F, Phibbs C, Courtney D, Lyles KW, May C, et al. A controlled trial of inpatient and outpatient geriatric evaluation and management. N Engl J Med. 2002; 346(12):905-12

21. Lok CE, Oliver MJ, Su J, Bhola C, Hannigan N, Jassal SV. Arteriovenous fistula outcomes in the era of the elderly dialysis population. Kidney Int. 2005;67(6): 2462-9.

22. Ocak G, Halbesma N, le Cessie S, Hoogeveen EK, van Dijk S, Kooman J, Dekker FW, Krediet RT, Boeschoten EW, Verduijn M. Haemodialysis catheters increase mortality as compared to arteriovenous accesses especially in elderly patients. Nephrol Dial Transplant. 2011;26(8):2611-7.

23. Xue JL, Dahl D, Ebben JP, Collins AJ. The association of initial hemodialysis access type with mortality outcomes in elderly Medicare ESRD patients. Am J Kidney Dis. 2003:42(5):1013-9.

24. Lamping DL, Constantinovici N, Roderick P, Normand C, Henderson L, Harris S, Brown E, Gruen R, Victor C. Clinical outcomes, quality of life, and costs in the North Thames Dialysis study of elderly people on dialysis: a prospective cohort study. Lancet (London, England). 2000;356(9241):1543-50.

25. Brown EA, Johansson L, Farrington K, Gallagher H, Sensky T, Gordon F, Da Silva-Gane M, Beckett N, Hickson M. Broadening options for long-term Dialysis in the elderly (BOLDE): differences in quality of life on peritoneal dialysis compared to haemodialysis for older patients. Nephrol Dial Transplant. 2010;25(11):3755-63.

26. Berger JR, Hedayati SS. Renal replacement therapy in the elderly population. Clin J Am Soc Nephrol. 2012;7(6):1039-46.
Ready to submit your research? Choose BMC and benefit from:

- fast, convenient online submission

- thorough peer review by experienced researchers in your field

- rapid publication on acceptance

- support for research data, including large and complex data types

- gold Open Access which fosters wider collaboration and increased citations

- maximum visibility for your research: over $100 \mathrm{M}$ website views per year

At BMC, research is always in progress.

Learn more biomedcentral.com/submissions 